\title{
Model Tests on the Antibreaking Countermeasures for Tunnel Lining Across Stick-Slip Faults
}

\author{
Guang-yao Cui $\mathbb{D}$, ${ }^{1}$ Xue-lai Wang $\mathbb{D},{ }^{1}$ Zheng-zheng Wang $\mathbb{D}^{2},{ }^{2}$ and Dao-yuan Wang $\mathbb{D}^{3}$ \\ ${ }^{1}$ School of Civil Engineering, North China University of Technology, Beijing 100144, China \\ ${ }^{2}$ School of Civil Engineering, Dalian University of Technology, Dalian 116024, China \\ ${ }^{3}$ Department of Civil Engineering, Hebei Jiaotong Vocational and Technical College, Shijiazhuang, Hebei 050091, China
}

Correspondence should be addressed to Xue-lai Wang; jjlam124@163.com

Received 12 October 2019; Accepted 22 January 2020; Published 11 February 2020

Academic Editor: Victor M. Castaño

Copyright (c) 2020 Guang-yao Cui et al. This is an open access article distributed under the Creative Commons Attribution License, which permits unrestricted use, distribution, and reproduction in any medium, provided the original work is properly cited.

In order to improve the structural safety and stability of the tunnels crossing stick-slip fault, an indoor model test on the effect of tunnel antibreaking measures under the influence of fault stick-slip movements was conducted. Using contact pressure, longitudinal strain, and safety factor, the antibreaking effect of tunnels was compared and analyzed under 5 kinds of operating conditions, mainly including no measures, structural strengthening, structural strengthening and reducing dislocation layer, structural strengthening and reducing dislocation joint, structural strengthening and reducing dislocation layer, and reducing dislocation joint. The results showed that the longitudinal strain and contact pressure of the tunnel changed markedly (from severe change to more uniform change) when the reducing dislocation measures were adopted in the test, reducing dislocation layer/ joint or reducing dislocation layer and reducing dislocation joint. The effect of reducing the fault stick-slip dislocation on the tunnel structure is very limited by only taking structure strengthening measures. The effect of reducing the fault stick-slip dislocation on the tunnel structure is obvious by using the reducing dislocation method, and the minimum safety factor is increased by more than 8 times. The effect of resisting and reducing the fault stick-slip dislocation on the tunnel structure is remarkable by adopting the measures of the structural strengthening and reducing dislocation layer and reducing dislocation joint, and the minimum safety factor is increased by more than 25.45 times. The results can provide reference for the design of antibreaking for the stick-slip fault tunnel in high earthquake intensity and dangerous mountainous areas.

\section{Introduction}

In recent years, more and more tunnels in the world pass through active faults. In China, the transportation infrastructure in the West has been developed continuously, and the traffic lifeline projects in high earthquake intensity and dangerous mountainous areas have been vigorously carried out. Tunnels crossing active faults have emerged, such as the Lanjiayan Tunnel from the highway of Mianzhu to Maoxian in Sichuan Province (through the Longmen Mountain Branch Fault), the Erlangshan Tunnel on the Yakang highway (through the Baohuang and other active faults), and the series of tunnels on the Jianchuan-Tibet Railway (through the Longmen Mountain, Xianshuihe, Jinsha River, Basu, and other active faults) [1-5].
Strong earthquakes can induce the activation of stick-slip faults [6]. The stick-slip dislocation of faults is the most important factor leading to serious damage of tunnel structures, and strong earthquake vibration is the second major factor. Therefore, it is necessary to systematically study the antibreaking technology of the stick-slip fault tunnels in order to improve the structural safety and stability.

The shearing force and displacement caused by the fault stick-slip dislocation are the main reasons for structural damage of tunnels $[7,8]$. The antibreaking measures (such as structural strengthening or surrounding rock strengthening) can effectively resist many adverse influences induced by the stick-slip fault. The reducing dislocation measures can reduce the transmission of shear force and forced 
displacement [9, 10]. Some former research results have shown that the active joints in the secondary lining of tunnel structures can effectively reduce longitudinal dislocation, while the damping layers between the primary supports and the secondary linings can reduce lateral dislocation [11-14].

Currently, only few scholars have made some researches on the antibreaking technique of the tunnel under the influence of the fault stick-slip dislocation. The damage mechanism of tunnel structure was not clear, and failure characteristics as well as damage mechanism of surrounding rock cannot be easily detected in spite of adopting many different numerical simulation techniques [15]. Thus, indoor model tests would be the best method to study the mechanical response of tunnel structures and surrounding rock under stick-slip fault circumstances. After the Erzincan earthquake, aseismic joints were applied in Bolu tunnel in Turkey, which was across the Bakacak active fault, to reduce the lateral displacement [16]. Moreover, a series of comparative studies on the Koohrangs hydraulic tunnel in Greece were carried out to prove the effect of dislocation joints on secondary lining with different spacing under the influence of the stick-slip fault [17].

Different from the former, a series of model tests were carried out to study the effect of antibreaking joints on the secondary lining to reduce lateral dislocation with the stickslip fault dislocation. Based on the vibration theories analysis and indoor model tests, the damping layer model, the principle of shock absorption, and the sensitivity of damping layer parameters are researched. Therefore, these series of researches are based on the F8 viscous slip fault of Longxi tunnel on Dujiangyan-Wenchuan highway, deeply studying the antibreaking technology for structural strengthening. It is of great significance to the further development of the antiseismic and disaster reduction technology in the high intensity and dangerous mountainous traffic tunnels.

\section{Model Test}

2.1. Overview of Prototype. Longxi tunnel is located in Chaping Mountain foot on Dujiangyan-Wenchuan highway, which topography is quite complicated. There are two faults (F3 Yingxiu fault and F2 Longxi fault) across the tunnel. Rock mass is fractured with many joints and fissures.

The F8 fault is a compressive stick-slip fault, striking east-west and dipping northward with an angle of 82 degrees. The fractured zone bandwidth is more than $10 \mathrm{~m}$, which is mainly composed of friction rock and fault gouge and is quite weak surrounding the rock. The hanging wall and footwall rock masses are of grade IV.

Longxi tunnel is a horseshoe tunnel with $11.90 \mathrm{~m}$ width and $10.14 \mathrm{~m}$ height. The primary support is C20 [18] shotcrete with a thickness of $20 \mathrm{~cm}$. The secondary lining is C25 [18] moulded concrete with a thickness of $60 \mathrm{~cm}$.

2.2. Test Purpose and Schemes. In order to study the antibreaking effect of tunnels by using the structural strengthening, reducing dislocation layer, or reducing dislocation joint of the stick-slip fault tunnel, we take the reducing dislocation joint of the interval of $12 \mathrm{~m}$ (the length of formwork trolley mainly consists of two kinds: $9 \mathrm{~m}$ and $12 \mathrm{~m}$ ) and the reducing dislocation layer of thickness of $10 \mathrm{~cm}$ as an example. Model tests were conducted on the secondary lining using C25 ( $E$ is $28 \mathrm{GPa}$ ) and C35 ( $E$ is $31.5 \mathrm{GPa}$ ) concrete, respectively. The test grouping is shown in Table 1.

2.3. Test Equipment. A self-designed inclined normal fault of inclined stick-slip fault test box was used for the test. The model box is $2.5 \mathrm{~m}$ length, $2.5 \mathrm{~m}$ width, and $2 \mathrm{~m}$ height. The test chamber is composed of hanging wall (movable) and footwall part (fixed), and the dip angle of the fault is 82 degrees (see Figure 1).

Static strain acquisition instrument is used to collect test data. The test sensors mainly include BE120-5AA strain gauges and DYB-1 Mini pressure boxes (see Figure 2).

2.4. Similarity Ratio. The experimental geometric similarity ratio is 30 (considering the experimental boundary effect). The elastic modulus similarity ratio is 45 (considering the severe similarity matching). The similarity ratio of other related physical quantities can be obtained according to the similarity theory (see Table 2) [19, 20].

2.5. Model Material. The secondary lining was simulated by gypsum mixture with specific water gypsum ratio (0.676 for $\mathrm{C} 25,0.599$ for C35), and the elastic modulus and compressive strength are similarity control indexes [21]. By the equivalent principle of flexural rigidity, the main ribs of the secondary lining are simulated by a special diameter steel wire (see Figure 3 ). The physical and mechanical parameters of lining model are shown in Table 3.

Polyethylene film is used to simulate a waterproofing board, and a sponge rubber sheet ( $1.7 \mathrm{~mm}$ thickness) is used to simulate the fault-reducing layer. The surrounding rock is simulated by using a thermal-thawing mixture of barite powder, fly ash, river sand, and oil (see Figure 4) [22, 23]. See Table 4 for basic mechanical parameters of similar materials.

This experiment mainly studies the influence and countermeasure of the fault stick-slip dislocation on the tunnel in the rock mass of the hanging wall and footwall and does not do research on the surrounding rock of the fault rupture zone and the tunnel structure. Therefore, this experiment uses two layers of PVC plastic plates (evenly coated with butter) to simulate the effect of the fault stick-slip dislocation (see Figure 5).

2.6. Measuring Schemes. Arrangement of testing section and measuring points are shown in Figure 6 . The lateral strain gauges ( $Y$, each of the two sides of the secondary lining is provided with a piece), a longitudinal strain gauge ( $Z Y$, the outer surface of the secondary lining), and an earth pressure cell ( $T$, between the primary support and the secondary lining) are laid in the vault. A pair of lateral strain gauges is arranged at the inner and outer sides of the side wall and the inverted arch. 
TABle 1: Test schemes.

\begin{tabular}{|c|c|c|}
\hline $\begin{array}{l}\text { Operating } \\
\text { conditions }\end{array}$ & Experiment content & Remarks \\
\hline 1 & The concrete of the secondary lining is C25 & Contrast condition \\
\hline 2 & The concrete of the secondary lining is C35 & Structural strengthening to antibreaking \\
\hline 3 & $\begin{array}{l}\text { The concrete of the secondary lining is C35, adopting the reducing } \\
\text { dislocation layer of the thickness of } 10 \mathrm{~cm}\end{array}$ & $\begin{array}{l}\text { Structural strengthening to antibreaking and } \\
\text { lateral reducing dislocation joint }\end{array}$ \\
\hline 4 & $\begin{array}{l}\text { The concrete of the secondary lining is } \mathrm{C} 35 \text {, adopting the reducing } \\
\text { dislocation joint of the interval of } 12 \mathrm{~m}\end{array}$ & $\begin{array}{l}\text { Structural strengthening to antibreaking and } \\
\text { longitudinal reducing dislocation joint }\end{array}$ \\
\hline 5 & $\begin{array}{c}\text { The concrete of the secondary lining is } \mathrm{C} 35 \text {, adopting the reducing } \\
\text { dislocation layer of the thickness of } 10 \mathrm{~cm} \text { and the reducing } \\
\text { dislocation joint of the interval of } 12 \mathrm{~m}\end{array}$ & $\begin{array}{l}\text { Structural strengthening to antibreaking, } \\
\text { longitudinal and lateral reducing dislocation joint }\end{array}$ \\
\hline
\end{tabular}

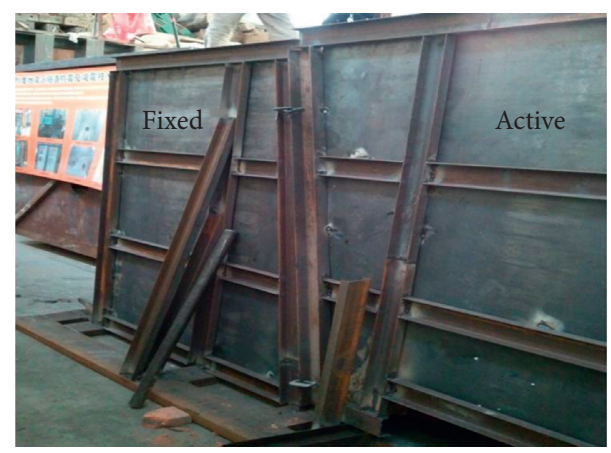

FIGURE 1: Stick-slip dislocation test box.

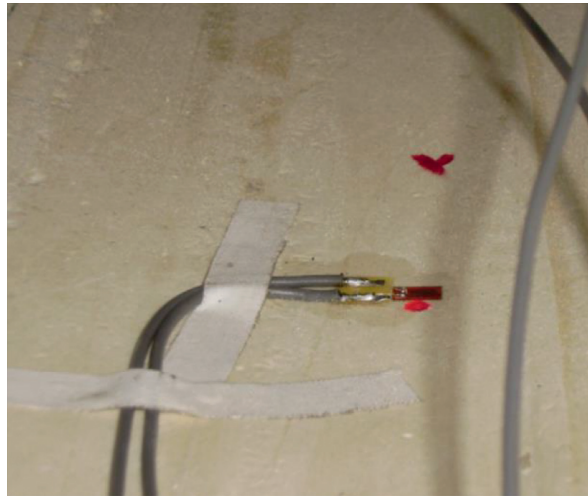

(a)

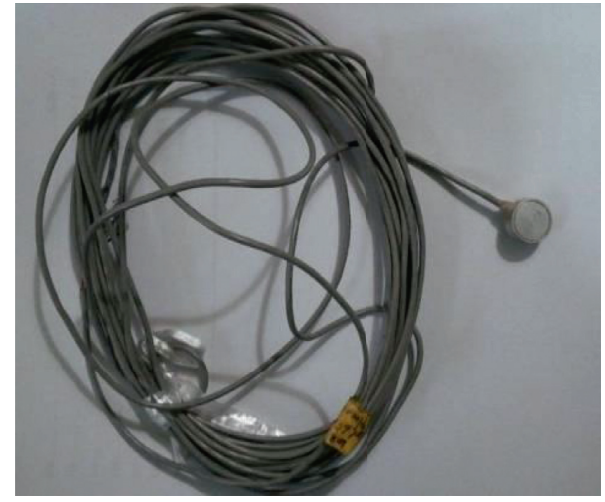

(b)

Figure 2: Measuring sensors. (a) Strain gauge. (b) Miniature pressure box.

TABle 2: Similarity coefficient of other related physical quantities.

\begin{tabular}{lcc}
\hline Type & Physical quantity & Similitude ratios \\
\hline \multirow{2}{*}{ Material characteristics } & Stress/cohesion & 45 \\
& Strain/Poisson ratio/internal friction angle & 1 \\
Geometric characteristics & Bulk density & 1.5 \\
& Angular displacement & 1 \\
Load & Area & 900 \\
\hline
\end{tabular}

2.7. Test Progress. First of all, the four jacks at the bottom of the hanging wall of the test chamber $(5 \mathrm{t}$, located at the bottom of the hanging wall at four corners, see Figure 7) were raised $5 \mathrm{~cm}$. Secondly, a similar material of the surrounding rock was tamped $(0.2 \mathrm{~m} /$ tamping $)$ to the bottom elevation of the inverted arch of the tunnel, laid the model of 


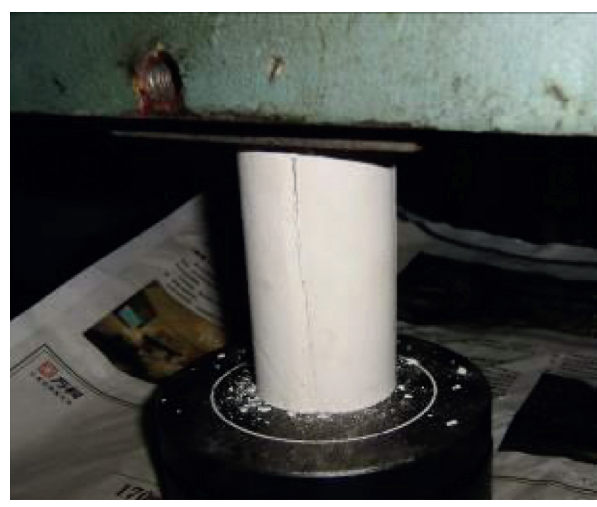

(a)

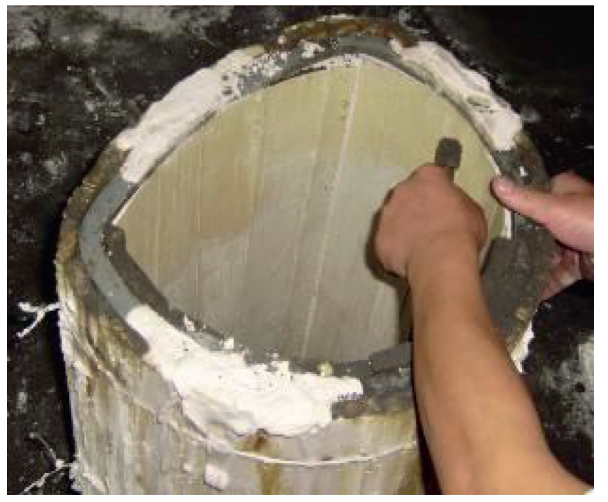

(c)

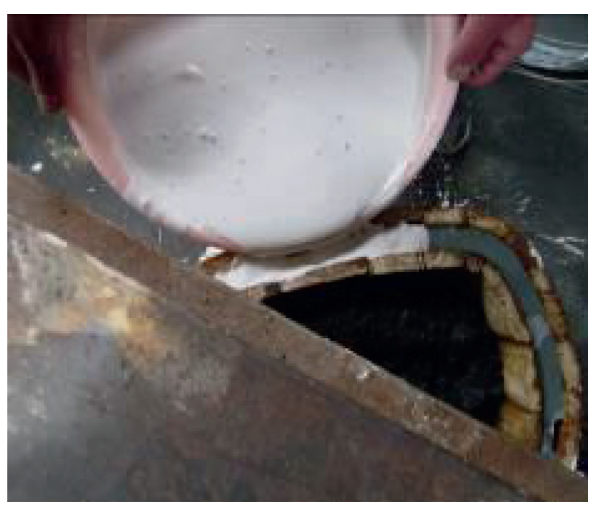

(b)

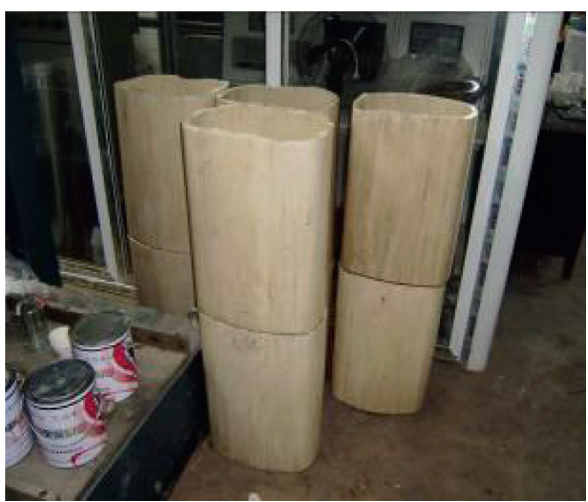

(d)

Figure 3: Secondary lining model. (a) Lining similar material mechanics test. (b) Lining model pouring. (c) Mold stripping. (d) Airing and lacquering.

TABLE 3: The physical and mechanical parameters of lining model.

\begin{tabular}{ccccc}
\hline & Reinforced concrete & Elastic modulus $(\mathrm{MPa})$ & Bulk density $\left(\mathrm{kN} \cdot \mathrm{m}^{-3}\right)$ & Poisson's ratio \\
\hline \multirow{2}{*}{ C25 } & Prototype & 29500 & 25 & 0.2 \\
& Similar materials & 671.3 & 16.9 & 0.2 \\
\hline \multirow{2}{*}{ C35 } & Prototype & 32500 & 25 & 0.2 \\
& Similar materials & 728.6 & 17.1 & 0.2 \\
\hline
\end{tabular}

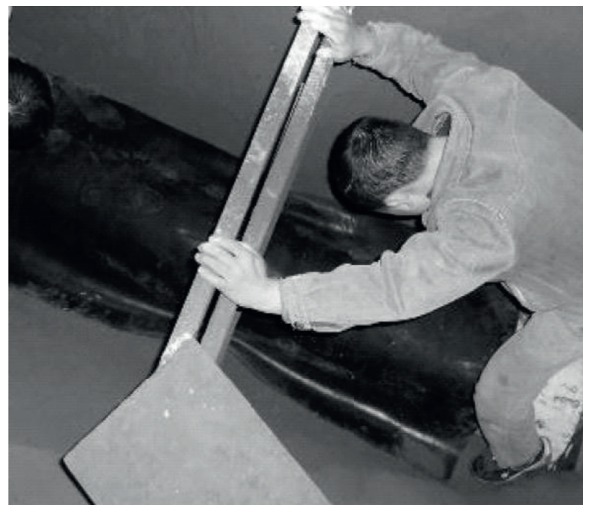

(a)

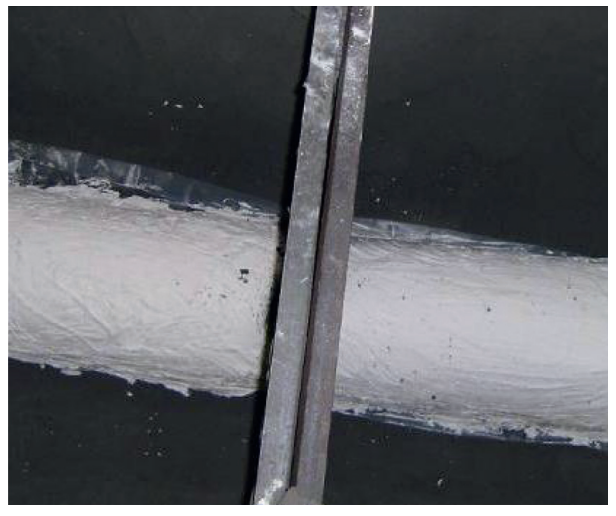

(b)

FIgURE 4: Test similar material. (a) The reducing dislocation layer. (b) Flashing and primary support. 
TABLE 4: Basic mechanical parameters of similar materials of surrounding rock.

\begin{tabular}{lccccc}
\hline \multicolumn{1}{c}{ Parameters } & Elastic modulus $(\mathrm{MPa})$ & Bulk density $\left(\mathrm{kN} \cdot \mathrm{m}^{-3}\right)$ & Cohesive force $(\mathrm{kPa})$ & Internal friction angle $\left(^{\circ}\right)$ \\
\hline Grade IV & Prototype & $1550 \sim 3300$ & $20 \sim 23$ & $240 \sim 650$ & $27 \sim 39$ \\
surrounding rock & Similar materials & 42.6 & 14.6 & $17 \sim 20$ & 30.3 \\
\hline Grade V & Prototype & $1400 \sim 2000$ & 12.7 & $20 \sim 200$ & $20 \sim 27$ \\
surrounding rock & Similar materials & 30.2 & 3.2 & 24.6 \\
\hline
\end{tabular}

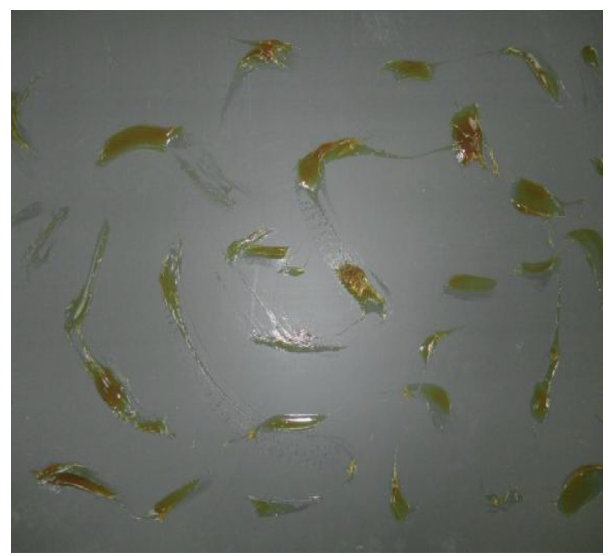

FIGURE 5: Simulation of stick-slip fault dislocation effect.

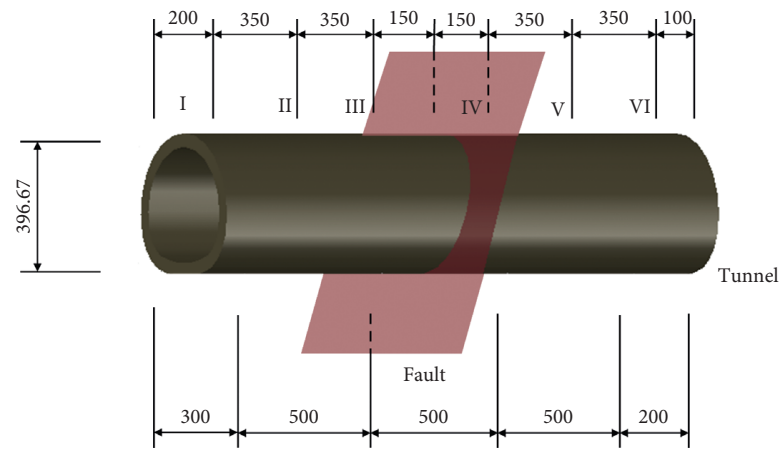

(a)

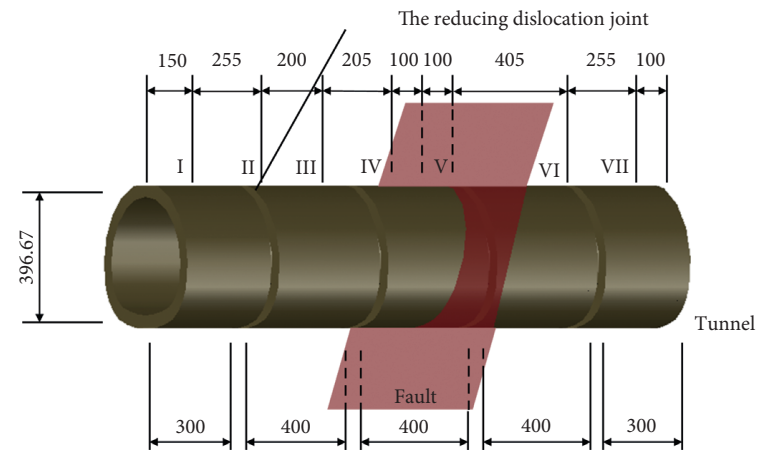

(b)

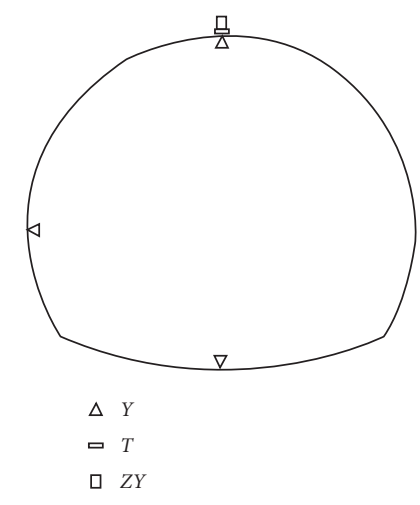

(c)

FIgURE 6: Arrangement of testing section and measuring points. (a) The measuring section of operating conditions 1 to 3 (unit: mm). (b) The measuring section of operating conditions 4 to 5 (unit: $\mathrm{mm}$ ). (c) Arrangement of the measuring points. 


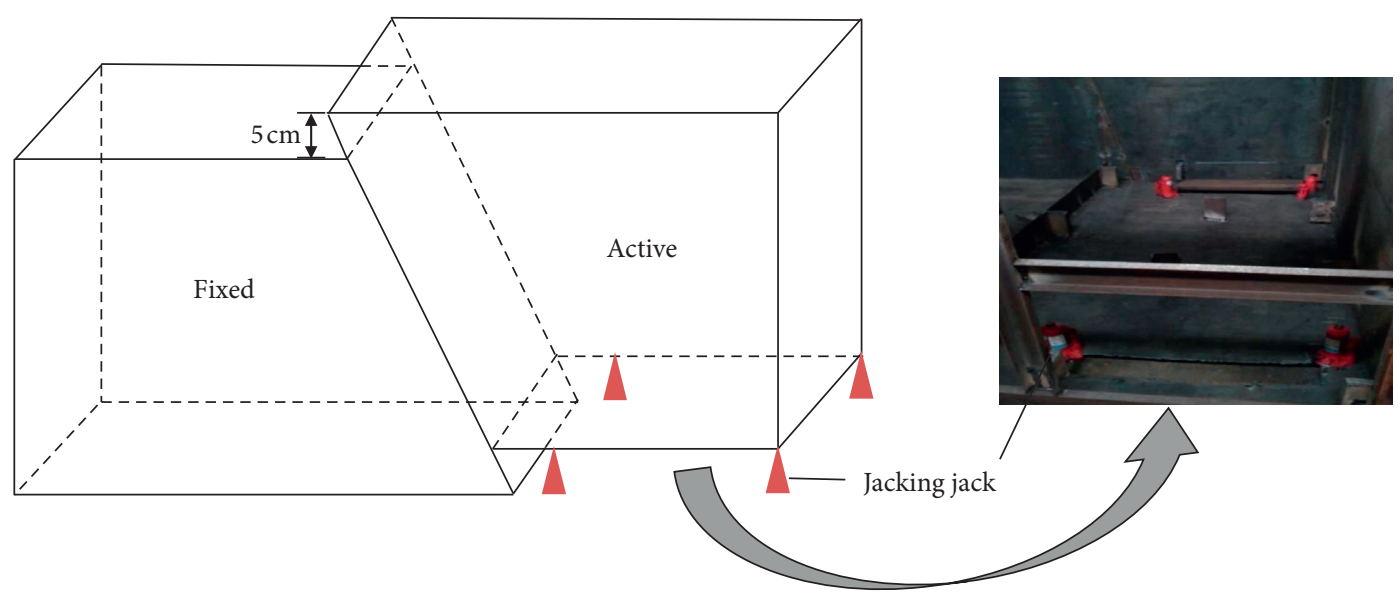

Figure 7: Test device and schematic diagram.

the secondary lining, the reducing joint/dislocation, flashing and test sensor, applied the primary support, and continued to tamp the surrounding rock to the designated elevation. Finally, the four jacks were lowered at the same time, and the hanging wall part occurred at the stick-slip dislocation along the fault plane, and the test was completed.

\section{Data Acquisition and Analysis}

3.1. Longitudinal Strains. After test, the longitudinal strain test data of each measuring section of the vault at different operating conditions are extracted, and the increase times are calculated (see Figure 8). The abscissa is positive number for the hanging wall part of the fault, and the negative number is the footwall part of the fault.

According to Figure 8:

(1) After the test, the longitudinal strain increase ratio of the vault of the hanging wall tunnel is larger than that of the footwall tunnel. The influence of the fault stick-slip dislocation on the hanging wall tunnel is greater than that of the footwall tunnel.

(2) After adopting the reducing dislocation measures (the reducing layer/joint or the reducing layer and the reducing joint of the operating conditions 3 to 5), the increase times of the longitudinal strain of the structure changed from severe to more uniform (along the longitudinal direction of tunnel).

The maximum value of the increase of the longitudinal strain at each point of the vault under different operating conditions is extracted, and the antibreaking effect of each operating condition is calculated (see Table 5).

According to Table 5,

(1) Only using structural strengthening measures (the operating condition 2), the longitudinal strain antibreaking effect $(14.41 \%)$ is much smaller than those of the structure strengthening and the reducing dislocation measures (the operating conditions 3 to 5 , and the effects of antibreaking were $98.07 \%$, $98.43 \%$, and $98.87 \%)$. This shows that the longitudinal strain antibreaking effect is limited by only using the structural strengthening measures.

(2) Only using the reducing dislocation measures of the operating conditions 3 to 5 (relative to the operating condition 2), the antibreaking effects of the longitudinal strain were $97.74 \%, 98.16 \%$, and $98.68 \%$, respectively. This shows that the longitudinal strain antibreaking effect of the reducing dislocation joint is slightly better than the use of the reducing dislocation layer. Adopting the antibreaking effects of the contact pressure of the reducing dislocation joint, at the same time, is the best. Adopting the antibreaking effects of the contact pressure of the reducing dislocation measures is over $97 \%$; the effect is obvious.

(3) At the same time using the structural strengthening, lateral reducing dislocation, and longitudinal reducing dislocation measures of the operating condition 5 (relative to the operating condition 1 ), the antibreaking effect of the longitudinal strain is the best; the effect is $98.87 \%$.

3.2. Contact Pressure. After the test, the contact pressure test data of each measuring section of the vault are extracted, and the increase times are calculated (see Figure 9).

According to Figure 9,

(1) After the test, the contact pressure increase ratio of the vault of the hanging wall tunnel is larger than that of the footwall tunnel. The influence of the fault stick-slip dislocation on the hanging wall tunnel is greater than that of the footwall tunnel.

(2) After adopting the reducing dislocation measures (the reducing layer/joint or the reducing layer and the reducing joint of the operating conditions 3 to 5), the increase times of the contact pressure of the structure changed from severe to more uniform (along the longitudinal direction of tunnel).

The maximum value of the increase contact pressure at each point of the vault under different operating conditions 


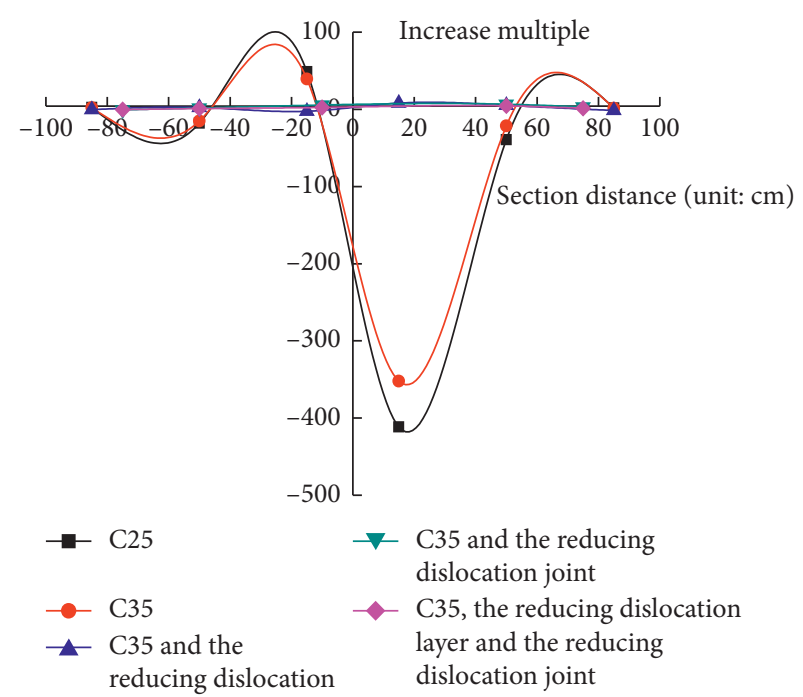

(a)

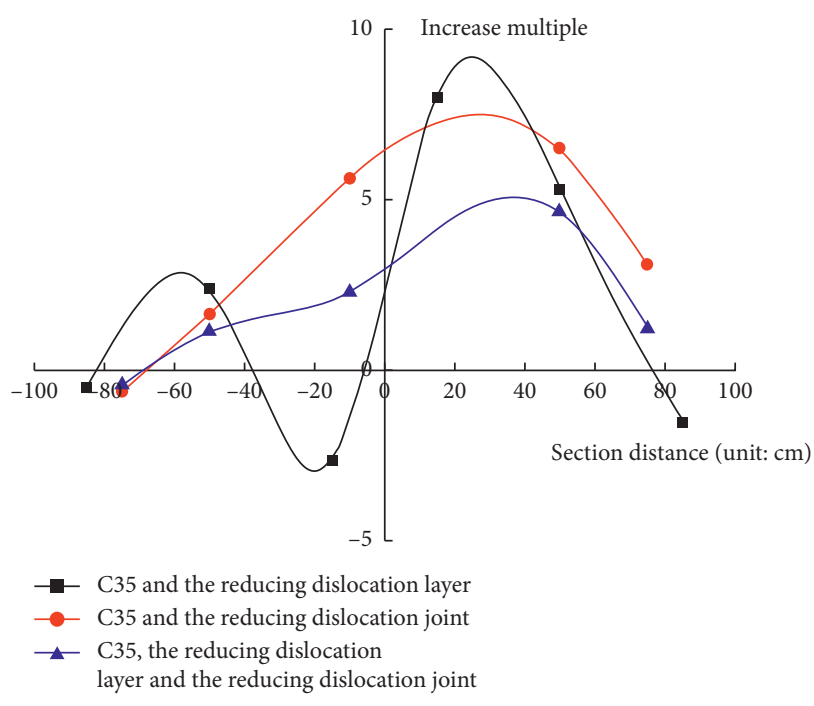

(b)

FIGURE 8: Increase multiple of longitudinal strain. (a) The operating conditions 1 to 5 . (b) The operating conditions 3 to 5.

TABle 5: Antibreaking effect of longitudinal strain.

\begin{tabular}{lccc}
\hline $\begin{array}{l}\text { Operating } \\
\text { conditions }\end{array}$ & $\begin{array}{c}\text { The maximum value of the increase } \\
\text { multiple of the longitudinal strain }\end{array}$ & $\begin{array}{c}\text { Antibreaking effect (\%) (relative to the } \\
\text { operating condition 1) }\end{array}$ & $\begin{array}{c}\text { Antibreaking effect (\%) (relative to } \\
\text { the operating condition 2) }\end{array}$ \\
\hline 1 & 411.39 & - & -16.83 \\
2 & 352.13 & 14.41 & - \\
3 & 7.96 & 98.07 & 97.74 \\
4 & 6.47 & 98.43 & 98.16 \\
5 & 4.64 & 98.87 & 98.68 \\
\hline
\end{tabular}

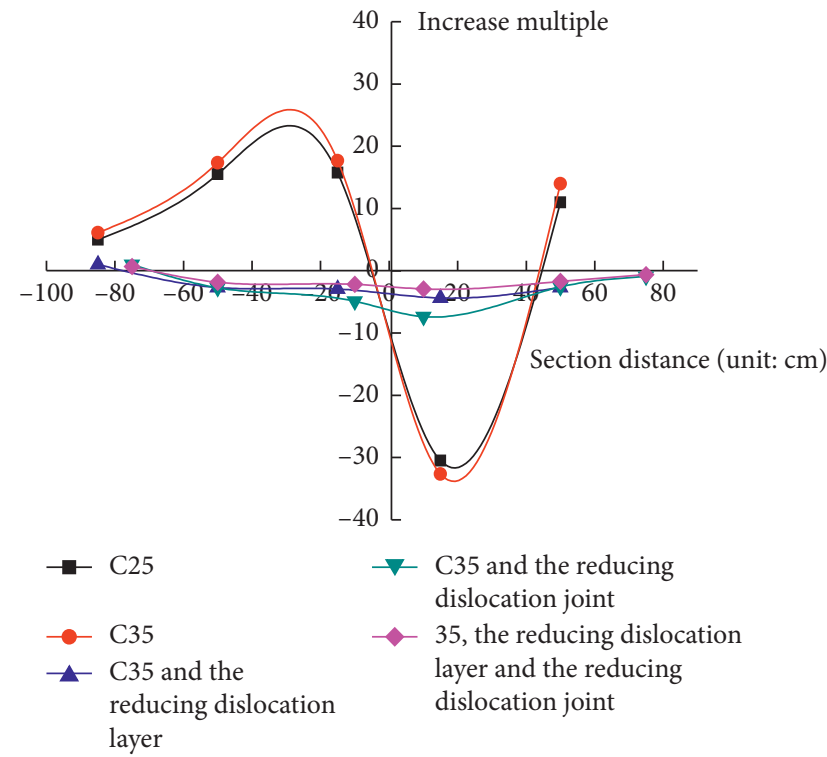

(a)

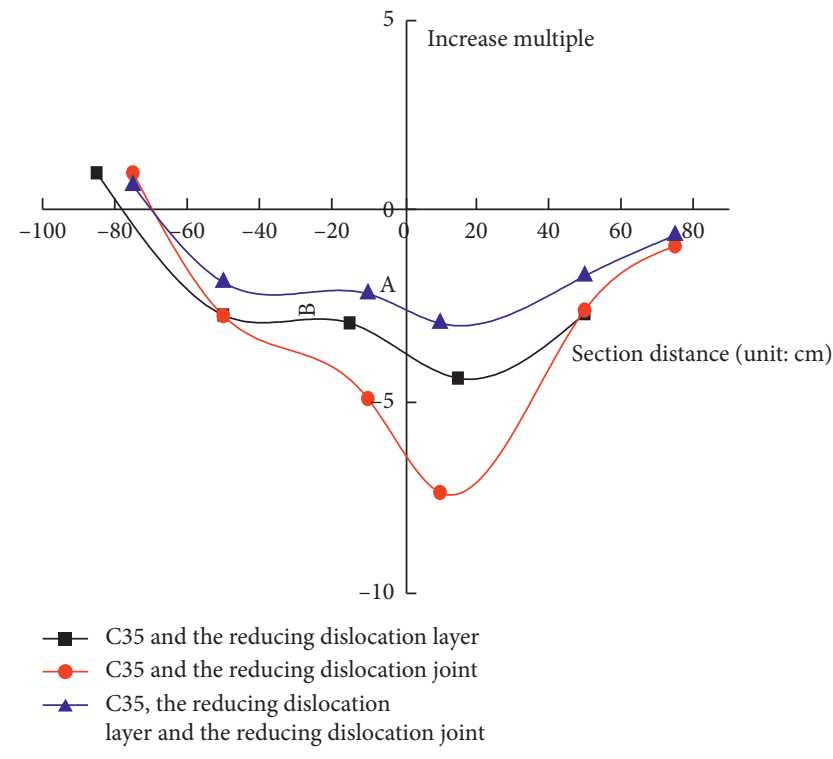

(b)

FIGURE 9: Increase multiple of contact pressure. (a) The operating conditions 1 to 5 . (b) The operating conditions 3 to 5. 
is extracted, and the antibreaking effect of each operating condition is calculated (see Table 6).

According to Table 6,

(1) Only using the structural strengthening measures (operating condition 2, relative to operating condition 1), the maximum value of the contact pressure increases slightly by 2.16 times $(32.66-30.50=2.16)$. This shows that the stress release of the surrounding rock has been further restricted after adopting the structural strengthening measures.

(2) Only using the reducing dislocation measures of the operating conditions 3 to 5 (relative to the operating condition 2), the antibreaking effects of the contact pressure were $86.65 \%, 77.47 \%$, and $91.04 \%$, respectively. This shows that the antibreaking effects of the contact pressure of the reducing dislocation layer are slightly better than the use of the reducing dislocation joint. Adopting the contact pressure antibreaking effect of the reducing dislocation joint, at the same time, is the best. Adopting the antibreaking effects of the contact pressure of the reducing dislocation measures is over $77 \%$; the effect is obvious.

3.3. Structural Internal Force. After the test, the measured data of lateral strain gauges of each measuring section of each operating condition are extracted, and we calculate the axial force, bending moment, and the value of the safety factor according to formulas (1) (4). The vault measuring point is taken as an example (see Figure 10) [24, 25].

The axial force and moment value of the lining structure are as follows:

$$
\begin{aligned}
& N=\frac{1}{2} E\left(\varepsilon_{\text {inside }}+\varepsilon_{\text {outside }}\right) b h, \\
& M=\frac{1}{12} E\left(\varepsilon_{\text {inside }}-\varepsilon_{\text {outside }}\right) b h^{2} .
\end{aligned}
$$

The safety factor of the lining structure is as follows:

$$
\begin{aligned}
& K N \leq \phi \alpha R_{a} b h, \\
& K N \leq \phi \frac{1.75 R_{l} b h}{6 e_{0} /(h-1)} .
\end{aligned}
$$

In the formula, the width of the section is expressed by $b$, and the width of the section is $1 \mathrm{~m}$. The thickness of section is expressed by $h$. The modulus of elasticity is expressed in $E$. The internal and external strains of the structure are expressed by $\varepsilon_{\text {inside }}$ and $\varepsilon_{\text {outside, }}$, respectively. Structural axial force is expressed by $N$. The bending moment is expressed by $M$. The ultimate compressive strength of concrete is expressed by $R_{a}$. The ultimate tensile strength of concrete is expressed by $R_{l}$. The safety factor is expressed by $K$. The longitudinal bending coefficient of components is expressed by $\varphi$. The influence coefficient of axial force eccentricity is expressed by $\alpha$.

The safety factor of the hanging wall tunnel vault of each operating condition is lower than that of the footwall tunnel,

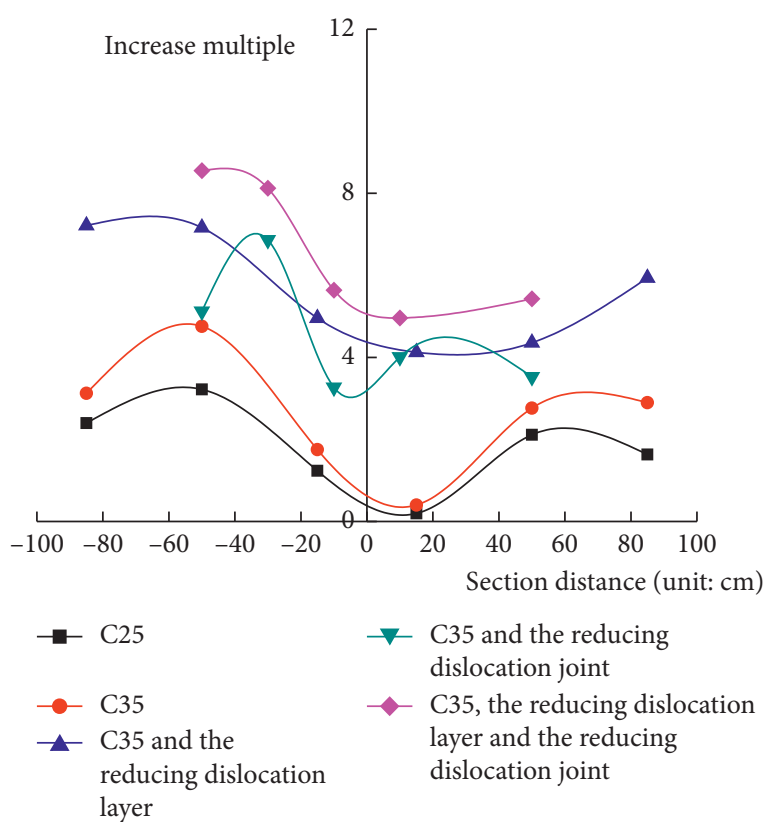

Figure 10: Safety factor of tunnel vault.

and the hanging wall tunnel is more affected by the fault stick-slip dislocation than the footwall tunnel.

The minimum value of safety factor in each working condition is extracted, and the increase multiple of minimum value of the safety factor is calculated (see Table 7).

According to Table 7,

(1) Only using structural strengthening measures (the operating condition 2 , and relative to the operating condition 1), the increase multiple of minimum value of the safety factor is only 2.06 times; it is much smaller than that of the structure strengthening and the reducing dislocation measures (the operating conditions 3 to 5). And the increase multiple of the minimum value of the safety factor was 21.16 times, 16.18 times, and 25.45 times. It shows that the effect of resistance to the fault stick-slip dislocation on the internal force of tunnel structures is limited by only adopting the structural strengthening measures.

(2) Only using the reducing dislocation measures of the operating conditions 3 to 5 (relative to the operating condition 2), the increase multiple of minimum value of the safety factor was 10.29 times, 8.15 times, and 12.37 times, respectively. This shows that adopting the reducing dislocation layer to reduce the fault stick-slip dislocation effect on internal force of tunnel structure is superior to the reducing dislocation joint. The increase multiple of minimum value of the structural safety factor is the largest by adopting the reducing dislocation and the reducing dislocation joint at the same time. The effect of reducing the fault stick-slip dislocation on the internal force of the tunnel structure by using the reducing dislocation measures is obvious, and the minimum structural safety factor is increased by more than 8 times. 
TABLE 6: Antibreaking effect of contact pressure.

\begin{tabular}{lccc}
\hline $\begin{array}{l}\text { Operating } \\
\text { conditions }\end{array}$ & $\begin{array}{c}\text { The maximum value of the increase } \\
\text { multiple of the contact pressure }\end{array}$ & $\begin{array}{c}\text { Antibreaking effect (\%) (relative to the } \\
\text { operating condition 1) }\end{array}$ & $\begin{array}{c}\text { Antibreaking effect (\%) (relative to the } \\
\text { operating condition 2) }\end{array}$ \\
\hline 1 & 30.50 & - & 6.61 \\
2 & 32.66 & -7.08 & - \\
3 & 7.36 & 85.70 & 86.65 \\
4 & 4.36 & 75.87 & 77.47 \\
5 & 2.93 & 90.41 & 91.04 \\
\hline
\end{tabular}

TABLE 7: Increase multiple of the minimum value of the safety factor.

\begin{tabular}{lccc}
\hline Operating conditions & The minimum value of the safety factor & $\begin{array}{c}\text { Increase multiple (relative to the } \\
\text { operating condition 1) }\end{array}$ & $\begin{array}{c}\text { Increase multiple (relative to the } \\
\text { operating condition 2) }\end{array}$ \\
\hline 1 & 0.19 & - & 0.49 \\
2 & 0.40 & 2.06 & - \\
3 & 4.13 & 21.16 & 10.29 \\
4 & 3.27 & 25.75 & 8.15 \\
5 & 4.96 & 25.45 & 12.37 \\
\hline
\end{tabular}

(3) At the same time, using the structural strengthening, lateral reducing dislocation, and longitudinal reducing dislocation measures of the operating condition 5 (relative to the operating condition 1), the increase multiple of minimum value of the structural safety factor is 25.45 times.

\section{Result Analysis and Discussion}

From the data results, we can clearly see that only structural strengthening measures to resist the impact of stick-slip dislocation on the internal force of tunnel structure are very limited. The dislocation can be reduced to a certain extent by using the reducing dislocation layer or reducing dislocation joint. From the data analysis results of this paper, the use of reducing dislocation layer is better than the use of reducing dislocation joint in reducing the impact of fault stick-slip on the internal force of the tunnel structure, which is because the reducing dislocation layer is for the overall layout of the tunnel, and there is a reducing dislocation layer at the fault location, which can play a direct role in the fault reduction, but there is also a reducing dislocation layer at the non-fault location, which can continue to reduce the force caused by dislocation displacement. However, the reducing dislocation joint is interval arrangement, and the reducing dislocation joint is not located in the dislocation position. The reducing dislocation joint does not directly reduce the dislocation displacement, and the dislocation displacement is indirectly reduced by the reducing dislocation joint on both sides. If the measures of strengthening structure, reducing dislocation layer, and reducing dislocation joint are taken at the same time, the antibreaking effect is the best. In the actual project, the cost of reducing dislocation joint depends on the construction joint, which is almost zero, while the cost of reducing dislocation layer depends on the material properties, so the cost is suitable for the actual project. It should be emphasized that the quality of the reducing dislocation layer and joint depends on the parameters of the reducing dislocation measures (as thickness, spacing, etc.), and the specific selection of the reducing dislocation parameters should be discussed in detail according to the actual project.

\section{Conclusions}

(1) The hanging wall tunnel is more affected by the fault stick-slip dislocation than the footwall tunnel. The reducing dislocation measures (reducing dislocation layer/joint or reducing dislocation layer and reducing dislocation joint) were adopted; the longitudinal strain and the contact pressure along the longitudinal direction of the tunnel increase from severe change to uniform change.

(2) The effect of reducing the fault stick-slip dislocation on the internal force of the tunnel structure by only adopting the structural strengthening measures is limited. The effect of reducing the fault stick-slip dislocation on the internal force of the tunnel structure by only adopting the reducing dislocation (the reducing dislocation layer/joint or the reducing dislocation layer and the reducing dislocation joint) measures is obvious, and the antibreaking effect of the longitudinal strain is over $97 \%$, the contact pressure antibreaking effect is over $77 \%$, and the minimum structural safety factor is increased by more than 8 times.

(3) At the same time, the effects of structural strengthening, lateral reducing dislocation, and longitudinal reducing dislocation are taken to resist and reduce the influence of the fault stick-slip dislocation on the tunnel structure, and its effect is obvious. The antibreaking effect of the longitudinal strain is $98.87 \%$, and the antibreaking effect of the contact pressure is $90.41 \%$. The minimum increase of structural safety factor is 25.45 times.

(4) Considering the antibreaking effect and the cost of the actual project, we suggest that the measures of 
strengthening the structure, reducing dislocation layer, and reducing dislocation joint should be taken together in the actual tunnel engineering to prevent the stick-slip fault dislocation.

\section{Data Availability}

The data used to support the findings of this study are included within the article.

\section{Conflicts of Interest}

The authors declare that there are no conflicts of interest regarding the publication of this paper.

\section{Acknowledgments}

The authors appreciate the support from the National Natural Science Foundation of China (Nos. 51408008 and 51478277).

\section{References}

[1] Z. Z. Wang and C. Chen, "Fuzzy comprehensive Bayesian network-based safety risk assessment for metro construction projects," Tunnelling and Underground Space Technology, vol. 70, pp. 330-342, 2017.

[2] Z. Z. Wang, L. Jiang, and Y. Gao, "Shaking table test of seismic response of immersed tunnels under effect of water," Soil Dynamics and Earthquake Engineering, vol. 116, pp. 436-445, 2019.

[3] Z. Z. Wang, Y.-J. Jiang, C. A. Zhu, and T. C. Sun, "Shaking table tests of tunnel linings in progressive states of damage," Tunnelling and Underground Space Technology, vol. 50, pp. 109-117, 2015.

[4] Z. Z. Wang, Y. J. Jiang, and C. A. Zhu, "Seismic energy response and damage evolution of tunnel lining structures," European Journal of Environmental and Civil Engineering, vol. 23, pp. 1-13, 2019.

[5] H. J. Zhang, Z. Z. Wang, F. Lu, G. Y. Xu, and W. G. Qiu, "Analysis of the displacement increment induced by removing temporary linings and corresponding countermeasures," Tunnelling and Underground Space Technology, vol. 73, pp. 236-243, 2018.

[6] G. Y. Cui and X. L. Wang, "Model test study on the antibreaking technology of reducing dislocation layer for subway interval tunnel of the stick-slip fracture," Advances in Civil Engineering, vol. 2019, Article ID 4328103, 9 pages, 2019.

[7] B. S. Ju, W. Y. Jung, and M. H. Noh, "Probabilistic risk assessment: piping fragility due to earthquake fault mechanisms," Mathematical Problems in Engineering, vol. 18, pp. 255-263, 2015.

[8] M. Kiani, T. Akhlaghi, and A. Ghalandarzadeh, "Experimental modeling of segmental shallow tunnels in alluvial affected by normal faults," Tunnelling and Underground Space Technology, vol. 51, pp. 108-119, 2016.

[9] D. Y. Li, Z. Y. Han, X. L. Sun et al., "Dynamic mechanical properties and fracturing behavior of marble specimens containing single and double flaws in SHPB tests," Rock Mechanics and Rock Engineering, vol. 52, 2019.

[10] D. Y. Li, P. Xiao, Z. Y. Han, and Q. Zhu, "Mechanical and failure properties of rocks with a cavity under coupled static and dynamic loads," Engineering Fracture Mechanics, vol. 225, 2020.

[11] H. Chen, X. Li, W. Yan, S. Chen, and X. Zhang, "Shaking table test of immersed tunnel considering the geological condition," Engineering Geology, vol. 227, pp. 93-107, 2017.

[12] X.-q. Chen, J.-g. Chen, P. Cui et al., "Assessment of prospective hazards resulting from the 2017 earthquake at the world heritage site Jiuzhaigou Valley, Sichuan, China," Journal of Mountain Science, vol. 15, no. 4, pp. 779-792, 2018.

[13] Z. Chen, W. Chen, Y. Li, and Y. Yuan, "Shaking table test of a multi-story subway station under pulse-like ground motions," Soil Dynamics and Earthquake Engineering, vol. 82, pp. 111122, 2016.

[14] B. Li and Z. Z. Wang, "Numerical study on the response of ground movements to construction activities of a metro station using the pile-beam-arch method," Tunnelling and Underground Space Technology, vol. 88, pp. 209-220, 2019.

[15] B. Shan, Y. Zheng, C. Liu, Z. Xie, and J. Kong, "Coseismic Coulomb failure stress changes caused by the 2017 M7.0 Jiuzhaigou earthquake, and its relationship with the 2008 Wenchuan earthquake," Science China Earth Sciences, vol. 60, no. 12, pp. 2181-2189, 2017.

[16] M. R. Moghadam and M. H. Baziar, "Seismic ground motion amplification pattern induced by a subway tunnel Shaking table testing and numerical simulation," Soil Dynamics and Earthquake Engineering, vol. 83, pp. 81-97, 2016.

[17] M. Saiyar, P. Ni, W. A. Take, and I. D. Moore, "Response of pipelines of differing flexural stiffness to normal faulting," Géotechnique, vol. 66, no. 4, pp. 275-286, 2016.

[18] Ministry of Housing and Urban-Rural Construction of the People's Republic of China, GB 50010-2010 Code for Design of Concrete Structures, Ministry of Housing and Urban-Rural Construction of the People's Republic of China, Beijing, China, 2010, in Chinese.

[19] Z. Bao, Y. Yuan, H. Yu et al., "Multi-scale physical model of shield tunnels applied in shaking table test," Soil Dynamics and Earthquake Engineering, vol. 100, pp. 465-479, 2017.

[20] C. L. Xin, Z. Z. Wang, J. M. Zhou, and B. Gao, "Shaking table tests on seismic behavior of polypropylene fiber reinforced concrete tunnel lining," Tunnelling and Underground Space Technology, vol. 88, pp. 1-15, 2019.

[21] H. Xu, T. Li, L. Xia, J. X. Zhao, and D. Wang, "Shaking table tests on seismic measures of a model mountain tunnel," Tunnelling and Underground Space Technology, vol. 60, pp. 197-209, 2016.

[22] W.-P. Wen, C.-H. Zhai, S. Li, Z. Chang, and L.-L. Xie, "Constant damage inelastic displacement ratios for the nearfault pulse-like ground motions," Engineering Structures, vol. 59, pp. 599-607, 2014.

[23] H. J. Zhang, Z. Z. Wang, F. Lu et al., "Analysis of the displacement increment induced by removing temporary linings and corresponding countermeasures," Tunnelling and Underground Space Technology, vol. 73, pp. 236-243, 2019.

[24] China Architecture \& Building Press, China Architecture \& Building Press, GB50157-2013 Code for Design of Metro, China Architecture \& Building Press, Beijing, China, 2013, in Chinese.

[25] China Communications Press, China Communications Press, JTG D70-2004 Code for Design of Road Tunnel, China Communications Press, Beijing, China, 2004, in Chinese. 